\title{
WestVirginiaUniversity
}

THE RESEARCH REPOSITORY @ WVU

Graduate Theses, Dissertations, and Problem Reports

2019

\section{Estimating the Age of a Bloodstain using Droplet Digital PCR}

\author{
Kalee Rae Crampton \\ West Virginia University, krcrampton@mix.wvu.edu
}

Follow this and additional works at: https://researchrepository.wvu.edu/etd

Part of the Molecular Biology Commons

\section{Recommended Citation}

Crampton, Kalee Rae, "Estimating the Age of a Bloodstain using Droplet Digital PCR" (2019). Graduate Theses, Dissertations, and Problem Reports. 3872.

https://researchrepository.wvu.edu/etd/3872

This Thesis is protected by copyright and/or related rights. It has been brought to you by the The Research Repository @ WVU with permission from the rights-holder(s). You are free to use this Thesis in any way that is permitted by the copyright and related rights legislation that applies to your use. For other uses you must obtain permission from the rights-holder(s) directly, unless additional rights are indicated by a Creative Commons license in the record and/ or on the work itself. This Thesis has been accepted for inclusion in WVU Graduate Theses, Dissertations, and Problem Reports collection by an authorized administrator of The Research Repository @ WVU. For more information, please contact researchrepository@mail.wvu.edu. 
Estimating the Age of a Bloodstain using Droplet Digital PCR

\title{
Kalee R. Crampton
}

\author{
Thesis submitted \\ to the Eberly College of Arts and Sciences \\ at West Virginia University \\ in partial fulfillment of the requirements for the degree of \\ Master of Science in \\ Forensic Biology \\ Clifton P. Bishop, Ph.D., Chair \\ Timothy Driscoll, Ph.D. \\ Tina Moroose, M.S. \\ Department of Biology \\ Morgantown, West Virginia \\ 2019
}

Keywords: Bloodstain, ddPCR, forensics, RNA

Copyright 2019 Kalee Crampton 


\title{
ABSTRACT \\ Estimating the Age of a Bloodstain using Droplet Digital PCR
}

\author{
Kalee Crampton
}

Biological evidence is extremely valuable in the investigation of a crime due to the presence of DNA. DNA evidence is considered the gold standard in court cases due to its ability to link a suspect to a piece of evidence. In addition to DNA evidence, biological stains have the potential to provide a temporal link between an individual and a crime scene. Previous studies have shown that relative rates of RNA degradation can be used in order to estimate the age of bloodstains. Here, we examined the ability of droplet digital PCR to be used in place of quantitative PCR in such an assay. Droplet digital PCR was unsuccessful in estimating the age of a bloodstain due to the difficulty associated with multiplexing linked targets. We also found that comparing rates of mRNA to rRNA degradation was not possible due to the large difference in abundance of the two types of RNA and the dynamic range of the instrument. Although droplet digital PCR was unsuccessful as a tool to estimate the age of a bloodstain, this work still provides valuable information for the refinement of an assay that can estimate the age of biological fluid stains. 


\section{Acknowledgements}

I would first like to thank my research advisor, Dr. Clif Bishop, for coming up with the idea behind this research, and for providing guidance throughout my time as a graduate student. You pushed me to become independent and confident in myself both as a scientist and as a person, and for that I am extremely grateful. I would also like to thank past graduates of the Bishop lab for laying much of the groundwork that my project has built upon. A tremendous amount of thanks to Dr. Timothy Driscoll for allowing me to use his droplet digital PCR machine and for providing invaluable experimental design advice; this project would not have been possible without your help. A special thank you to Dr. Victoria Verhoeve for always being my sounding board when the going got rough. I learned a lot from you over the years and your support and encouragement were greatly appreciated. I would also like to extend thanks to Tina Moroose, for being a member of my committee and providing valuable insight into the world of forensic science. I would also like to thank my lab mate, Jordan Flesher, for agreeing to continue this research, and for keeping me company the past year.

Thank you to the West Virginia University biology department as a whole. I have enjoyed my time here, and this would not have been possible without the positive environment fostered by the faculty and other graduate students.

Finally, I would like to thank my family and friends for their support throughout this process. I would not have been able to do this without your support. 


\section{Table of Contents}

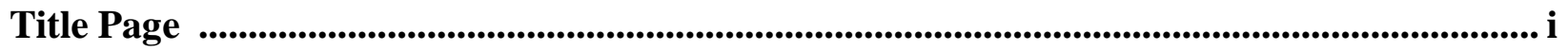

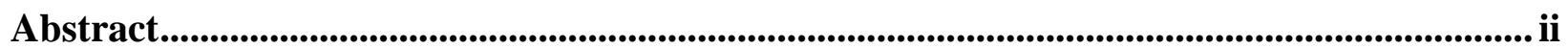

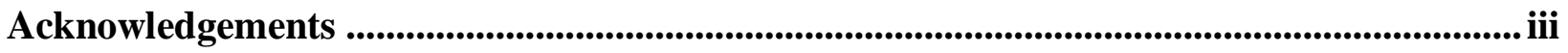

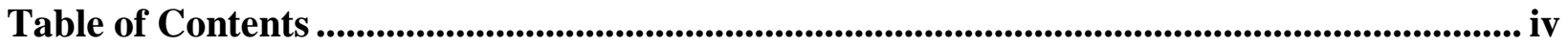

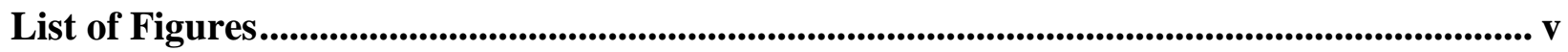

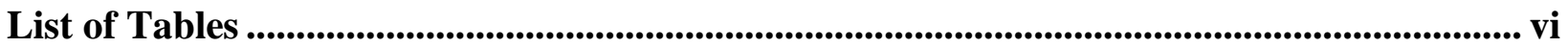

Chapter 1: Comparison of large to small fragments of Beta-actin mRNA and 18S rRNA ... 1

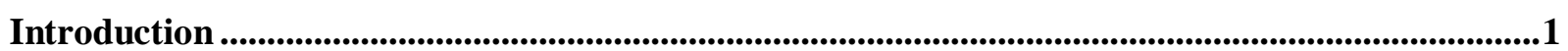

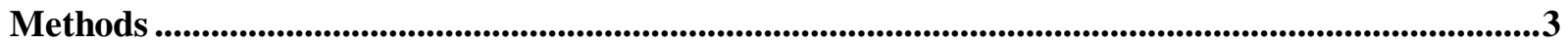

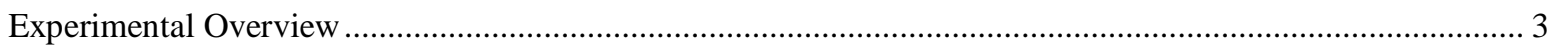

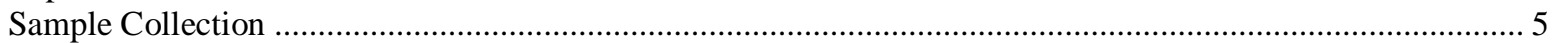

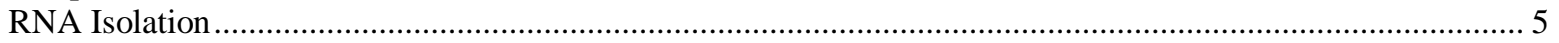

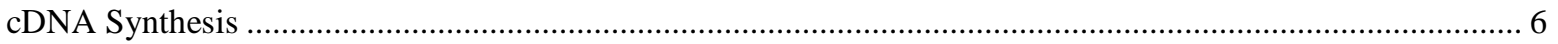

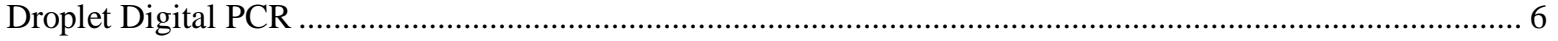

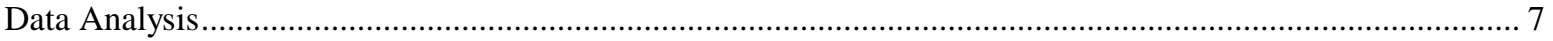

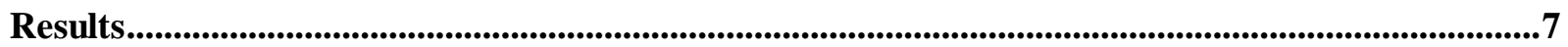

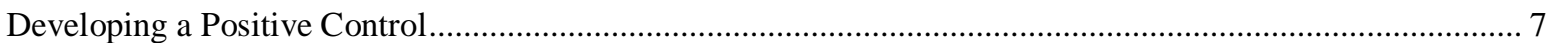

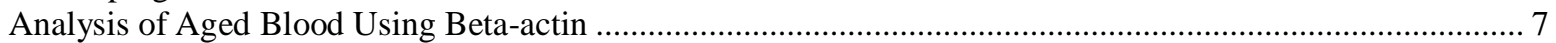

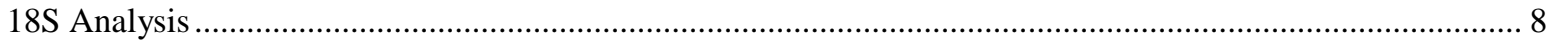

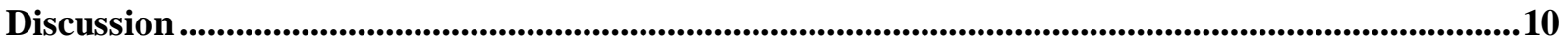

Chapter 2: Comparison of different RNA molecules to estimate the age of a bloodstain.... 13

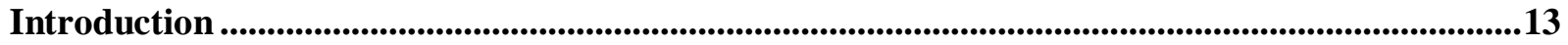

Methods ..................................................................................................................................................................14

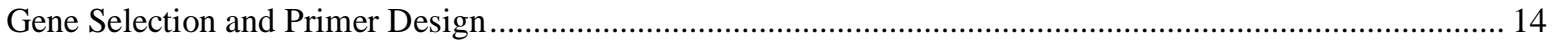

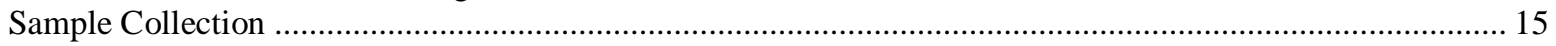

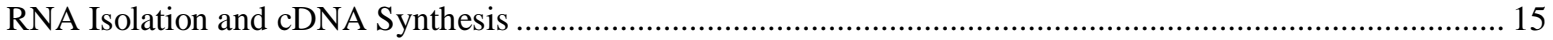

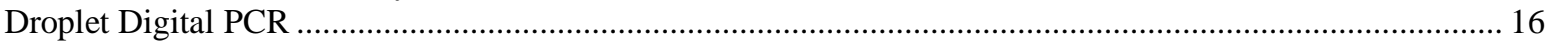

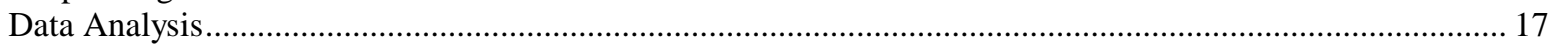

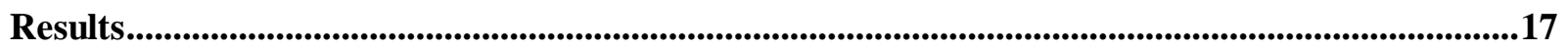

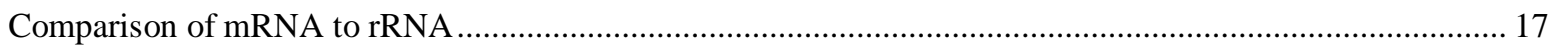

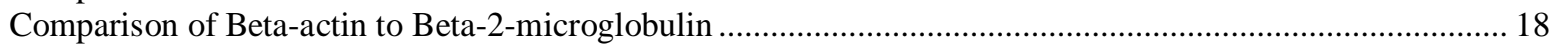

Discussion .................................................................................................................................................................19

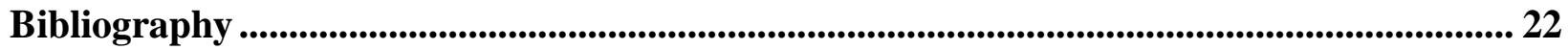




\section{List of Figures}

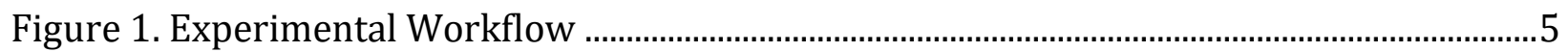

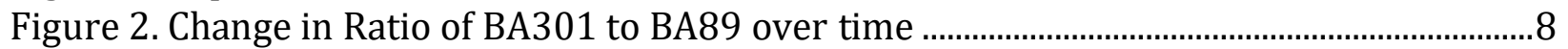

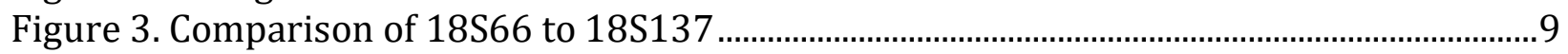

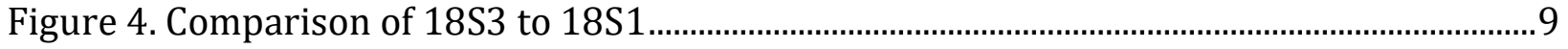

Figure 5. Comparison of Beta-actin to 18S transcripts ................................................................... 18

Figure 6. Average ratio of B2Ma to BA89 in aged bloodstains.................................................... 19 


\section{List of Tables}

Table 1. Primer Sequences for small and large fragments of Beta-actin and 18S RNA..............4 Table 2. Primer sequences for comparisons between different RNA species............................. 15 


\section{Comparison of large to small fragments of Beta-actin mRNA and 18S rRNA Introduction}

Within the field of forensic science, biological evidence is of large significance due to its ability to link a suspect to a crime via DNA analysis. Much advancement has been made with regard to DNA analysis and the ability to spatially link a suspect to a particular crime scene ${ }^{1}$. However, crime labs today are still left without a routine method to temporally link a suspect to a particular piece of biological evidence. There is a clear need for such an assay in the field of forensic science because often times there is an abundance of biological evidence at a scene, which may or may not be relevant depending on when it was left at the scene. This is particularly true in cases where there is a logical reason why DNA may have been left by an individual, such as when a crime scene is inside one's home.

Although no method has been widely adopted by crime laboratories thus far, there has been a plethora of research conducted attempting to determine the age of a bloodstain. The earliest attempts focused on correlating the color of an aged bloodstain with the time since deposition $^{2}$. While these attempts were extremely subjective and not very reliable, advances in technology have allowed for the development of more accurate colorimetric analyses, one of which allows for the estimation of a bloodstain using a smartphone ${ }^{3}$. Other attempts include examining changes in hemoglobin composition over time, analysis of serum proteins and hormones, and measuring solubility of the dried stain in water ${ }^{2}$. While each of these methods does have its own advantages, one common drawback is that these methods can only be applied to bloodstains and not to other biological fluids. Additionally, most of the attempts made to estimate the age of a bloodstain are only reliable for a short time period after deposition of the stain $^{2}$. 
Previously, the Bishop lab has shown that relative rates of RNA degradation could be used in order to estimate the age of a bloodstain ${ }^{2,4,5}$. This method involves comparing the relative ratio of an mRNA to an rRNA transcript as well as comparing the relative ratio of a small to large fragment of the same RNA species over time. As the RNA degrades the ratio of the larger fragment to the smaller fragment will decrease as will the ratio of mRNA to rRNA ${ }^{5}$. This method is advantageous over those previously mentioned because it has the potential to be useful over large periods of time; some research has shown that RNA suitable for PCR could be detected in bloodstains up to 15 years old ${ }^{6}$. Additionally, the use of housekeeping genes in this type analysis would allow for the assay to be applied to any type of biological fluid.

Although we have had some success using qPCR in order to estimate the age of bloodstains, there are still drawbacks to this approach. Using qPCR requires multiplex reactions containing primer and probe combinations for a small and large amplicon within the same RNA species; the larger the difference in size between the small and large amplicon, the more useful the assay will be for age determination. This type of assay presents a problem because it can result in preferential amplification of the smaller amplicon, which can cause unreliable results and limits the usefulness of the assay ${ }^{7}$ Quantitative PCR reactions can also be influenced by inhibitors that may be encountered often in forensic samples, such as indigo dye used in the production of denim jeans ${ }^{8}$.

Droplet digital PCR is a relatively new technology that can potentially be used to improve upon the qPCR assay previously developed by the Bishop lab. Droplet digital PCR works by partitioning a single reaction into approximately 20,000 nanoliter sized droplets which each function as independent reaction vessels. The PCR reaction is allowed to continue to endpoint and then the fluorescent amplitude of each droplet is recorded, and the droplets are 
scored as either positive or negative. Based on the proportion of positive droplets in the reaction and Poisson modeling, an estimate of the starting copy number of the target is provided ${ }^{9}$. This type of PCR allows for absolute quantification of a target as opposed to relative quantification and also has increased precision and sensitivity at low copy numbers ${ }^{10,11}$. Furthermore, ddPCR assays are less susceptible to inhibitors because they are run to endpoint before quantification occurs $^{8,12}$. Droplet digital PCR is also advantageous because the droplet partitioning allows for multiplexing using intercalating dyes rather than hydrolysis probes. This is because fluorescent amplitude of the droplets is directly related to the size of the amplicon contained within the droplet. Therefore multiplexing amplicons of different sizes results in two different droplet populations that can be quantified separately ${ }^{9}$.

Droplet digital PCR has the potential to improve upon previously design qPCR assays due to the droplet partitioning, sensitivity, and robustness to inhibitors of the ddPCR workflow. Here we aim to develop a ddPCR assay that can be used to estimate the age of a bloodstain.

\section{Methods}

\section{Experimental Overview}

The objective of this study was to compare large and small fragments on the same RNA molecule. Beta-actin mRNA and 18S rRNA were chosen as the two RNA molecules to be used in this study based on their previous success in qPCR assays ${ }^{5}$. The primer sets used in this assay were either previously designed by Anderson et al. (2011), or designed using Primer3 Plus primer design software (Table 1.). All primer sets were checked for specificity using primer blast through the National Center for Biotechnology Information (NCBI) and supplied by Integrated DNA Technologies (IDT). A gene-block including both Beta-actin amplicons was synthesized by IDT for use as a positive control. 
Because multiplexing can be achieved using an intercalating dye (evagreen) in ddPCR reactions, probes were not necessary. However, in order to multiplex two amplicons on the same RNA molecule, it is necessary that they segregate into separate droplets during the droplet generation phase of ddPCR. This necessitates second strand synthesis, a cleanup step, and the addition of a restriction enzyme that will cut the double stranded cDNA in between the two amplicons (Fig 1.). Restriction enzymes were identified using Restriction Mapper version 3 and were supplied by New England BioLabs; BsrBI was used for 18S comparisons and ScaI was used for Beta-actin comparisons. Temperature gradients were used in singleplex and for each multiplex reaction to determine the optimal annealing temperature for each assay. The optimal annealing temperature was the one which produced the most separation between droplet populations. If necessary, primer concentration was adjusted to achieve further separation of droplet populations. Dilution series of template were performed for the positive control, and cDNA samples with beta-actin and $18 \mathrm{~S}$ primer sets to ensure that the reaction was not being overloaded with template.

Table 1. Primer Sequences for small and large fragments of beta-actin and 18S RNA. * Indicates previously published primers ${ }^{5}$.

\begin{tabular}{|c|c|c|c|}
\hline Name & Gene & $\begin{array}{l}\text { Amplicon } \\
\text { Length }\end{array}$ & Primer Sequences \\
\hline BA301* & Beta-actin mRNA & $301 \mathrm{bp}$ & $\begin{array}{l}\text { FP: 5' CTT CAA CAC CCC AGC CAT GT 3' } \\
\text { RP: 5' CTC TTG CTC GAA GTC CAG GG 3' }\end{array}$ \\
\hline BA89* & Beta-actin mRNA & 89 bp & $\begin{array}{l}\text { FP: 5' TCA TTC CAA ATA TGA GAT GCA TTG T 3' } \\
\text { RP: 5' GGA CTG GGC CAT TCT CCT TAG 3' }\end{array}$ \\
\hline $18 S 66$ & 18S rRNA & $66 \mathrm{bp}$ & $\begin{array}{l}\text { FP: 5' GAA TTG ACG GAA GGG CACC } 3^{\prime} \\
\text { RP: 5' AGG TTT CCC GTG TTG AGT CAA ATT A } 3^{\prime}\end{array}$ \\
\hline $18 \mathrm{~S} 137$ & 18S rRNA & $137 \mathrm{bp}$ & $\begin{array}{l}\text { FP: 5' GTG CAT GGC CGT TCT TAG TT 3' } \\
\text { RP: 5' GAA CGC CAC TTG TCC CTC TA } 3^{\prime}\end{array}$ \\
\hline $18 \mathrm{~S} 1$ & $18 \mathrm{~S}$ rRNA & $63 \mathrm{bp}$ & $\begin{array}{l}\text { FP: 5' GGG ATC GGG GAT TGC AAT TA 3' } \\
\text { RP: 5' GCT TAT GAC CCG CAC TTA CT 3' }\end{array}$ \\
\hline $18 \mathrm{~S} 3$ & 18S rRNA & $221 \mathrm{bp}$ & $\begin{array}{l}\text { FP: 5' CAT TCG AAC GTC TGC CCT AT 3' } \\
\text { RP: 5' ATT CCA ATT ACA GGG CCT CG 3' }\end{array}$ \\
\hline
\end{tabular}



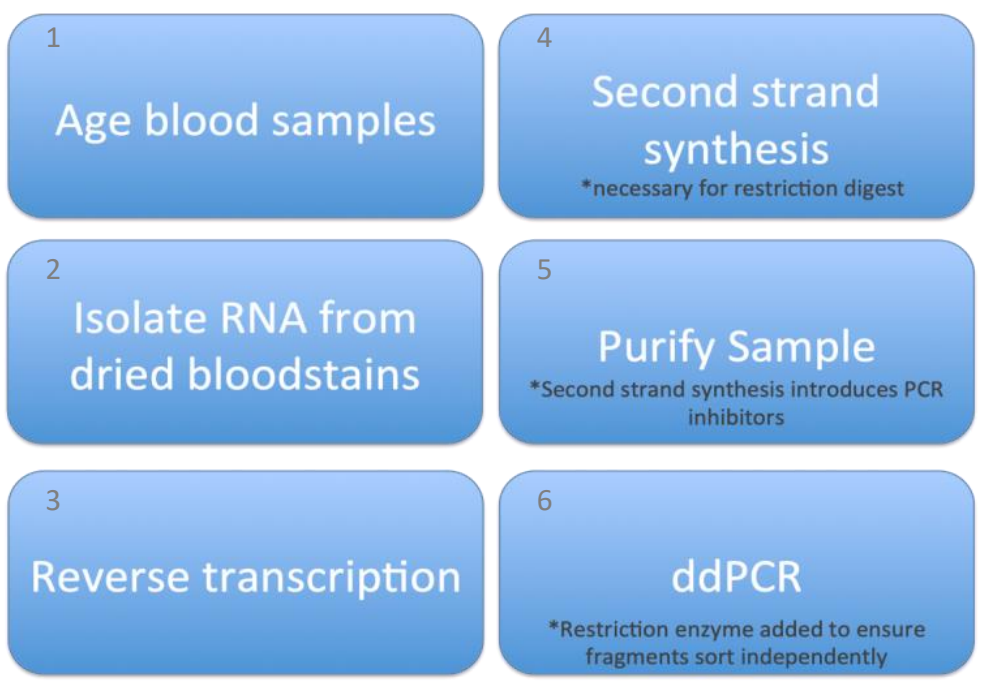

Figure 1. Experimental Workflow

\section{Sample Collection}

Blood was spotted on cotton cloth in $10 \mu \mathrm{L}$ aliquots from a male and female donor. The blood was allowed to age, and RNA was isolated from fresh, 7-day, 16-day, 23 day, and 38-dayold stains. Two biological replicates were used for each time point. The cotton cloth was kept at room temperature for the duration of the aging process.

\section{RNA Isolation}

Two spots of blood from each time point were cut from the cotton cloth and added to 200 $\mu \mathrm{L}$ of nuclease free water, $3 \mu \mathrm{L}$ of cold polyacryl carrier, and $750 \mu \mathrm{L}$ of RNAzol BD (Molecular Research Center). The samples were vortexed then incubated in a $50^{\circ} \mathrm{C}$ water bath for 10 minutes. One hundred microliters of 1-bromo-3-chloropropane (BCP) was added to the samples to assist in phase separation. The tubes were vortexed for 15 seconds and allowed to incubate at room temperature for 3 minutes. Following incubation, the samples were centrifuged at $12,000 \mathrm{xg}$ for 15 minutes. The aqueous layer was transferred to a new RNase free tube and 500 
$\mu \mathrm{L}$ of cold isopropanol was added; tubes were inverted to mix the aqueous layer and isopropanol and allowed to incubate at room temperature for 7 minutes. Samples were then centrifuged at $12,000 \mathrm{xg}$ for 8 minutes. After centrifugation, the supernatant was discarded, and $1 \mathrm{~mL}$ of $75 \%$ ethanol was added to wash the RNA pellet. The pellet and ethanol were briefly vortexed and then centrifuged for 5 minutes at $12,000 \mathrm{xg}$. The supernatant was removed, and the pellets were allowed to air dry for approximately 5 minutes. Forty microliters of RNase free water was added to the pellet and then incubated at $55^{\circ} \mathrm{C}$ for 10 minutes.

\section{cDNA Synthesis}

Immediately following RNA isolation, cDNA synthesis was performed. The iScript cDNA Synthesis Kit RT-qPCR (Bio-Rad) was used according to manufacturer's instructions. Five microliters of input RNA was added. Following the first strand synthesis, the second strand was synthesized using the NEBNext Ultra II Non-Directional RNA Second Strand Synthesis Module according to Manufacturer's instructions (New England BioLabs, Inc.). The second strand synthesis product was then purified using the GeneJet PCR Purification Kit in order to remove PCR inhibitors introduced by the second strand synthesis reaction.

\section{Droplet Digital PCR}

Samples were prepped at a volume of $22 \mu \mathrm{L}$ using the QX200 ddPCR EvaGreen Supermix. Two technical replicates were prepared for each biological replicate. Following preparation of all PCR reactions, the samples were incubated at room temperature for 15 minutes before being added to a droplet generation cartridge along with $70 \mu \mathrm{L}$ of droplet generation oil. After droplet portioning by the QX 200 Droplet Generator (Bio-Rad), the samples were transferred to a 96 well plate using a multichannel pipet. The plate was heat-sealed and PCR was performed using the C1000 Touch Thermal Cycler (Bio-Rad) under the following cycling 
conditions: $95^{\circ} \mathrm{C}$ for 5 minutes, 40 cycles of $95^{\circ} \mathrm{C}$ for 30 seconds then $57^{\circ}$ for 1 minute, $4^{\circ} \mathrm{C}$ for 5 minutes, $90^{\circ} \mathrm{C}$ for 5 minutes, and then an infinite hold at $4^{\circ} \mathrm{C}$. The lid temperature was set to $105^{\circ} \mathrm{C}$ and the reaction volume was set at $40 \mu \mathrm{L}$.

\section{Data Analysis}

Droplet digital PCR data was analyzed using the QuantaSoft Analysis Pro software. Thresholds were drawn between droplet populations and the software used Poisson statistics to identify the quantity of starting material present for each amplicon in copies per microliter ${ }^{9}$. The ratio of large to small fragment was calculated for each sample and these ratios were used for downstream statistical analyses. An ANOVA was performed using ratios of aged blood samples in order to determine if the ratio of large to small fragment was significantly different for different ages of bloodstains.

\section{Results}

\section{Developing a Positive Control}

The gene-block, or synthetic double-stranded DNA fragment, from IDT containing both the small and large Beta-Actin amplicons was used to establish a baseline ratio of the large BetaActin amplicon (BA301) to the small Beta-Actin amplicon (BA89); this ratio was .288 (s=.04) with an $\mathrm{n}$ of 9 samples. Quantification of each amplicon did not appear to vary from singleplex to duplex reactions, but this was not extensively investigated in this study.

$$
\text { Analysis of Aged Blood Using Beta-Actin }
$$

Two technical replicates and two biological replicates were measured for each time point; any samples with low droplet counts were excluded from the analysis. A one-way analysis of 
variance (ANOVA) was used to determine that the age of the bloodstain had no significant effect on the ratio of BA301 to BA89 present in the sample $[\mathrm{F}=.8361, \mathrm{p}=.5851]$ (Fig.2).

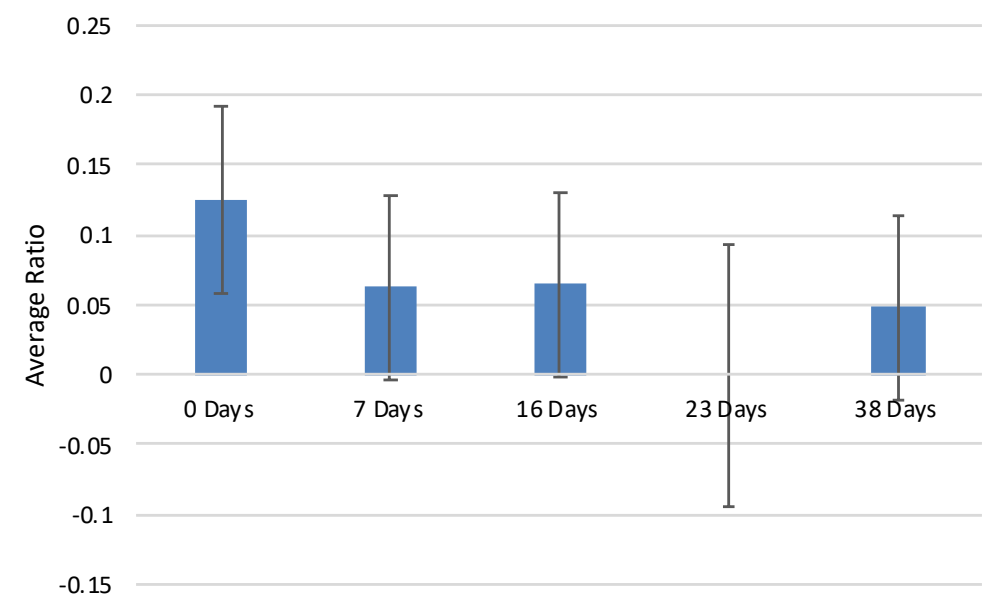

Figure 2. Change in Ratio of BA301 to BA89 over time. There was no significant decrease in the ratio over time. Bars represent standard deviation.

\section{S Analysis}

The previously studied primer sets used for $18 \mathrm{~S}$ analysis were not suitable for multiplexing with evagreen in ddPCR due to the lack of droplet separation that was achieved (Fig. 3). When comparing 18S1 and 18S3 primer sets, sufficient droplet separation was achieved (Fig. 4) and the average ratio of $18 \mathrm{~S} 3$ to $18 \mathrm{~S} 1$ product was determined to be $.153(\mathrm{~s}=.222)$. In this case, the standard deviation was determined to be too high to use these primer sets for an analysis of aged blood samples. 


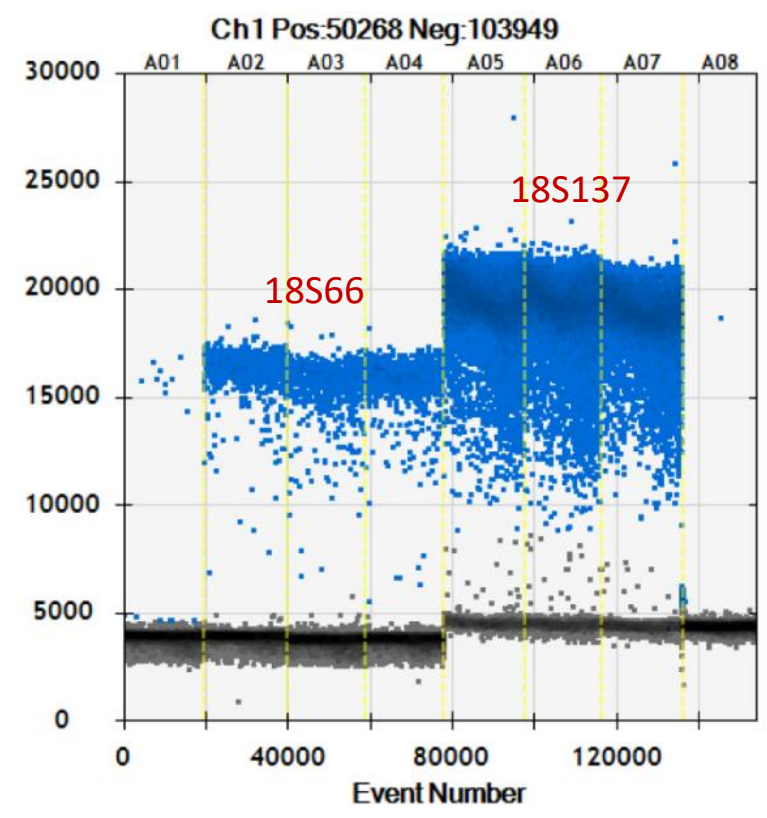

Figure 3. Comparison of 18 S66 to 18 S137. These two primer sets are not able to be multiplexed due to the lack of separation between droplet populations.
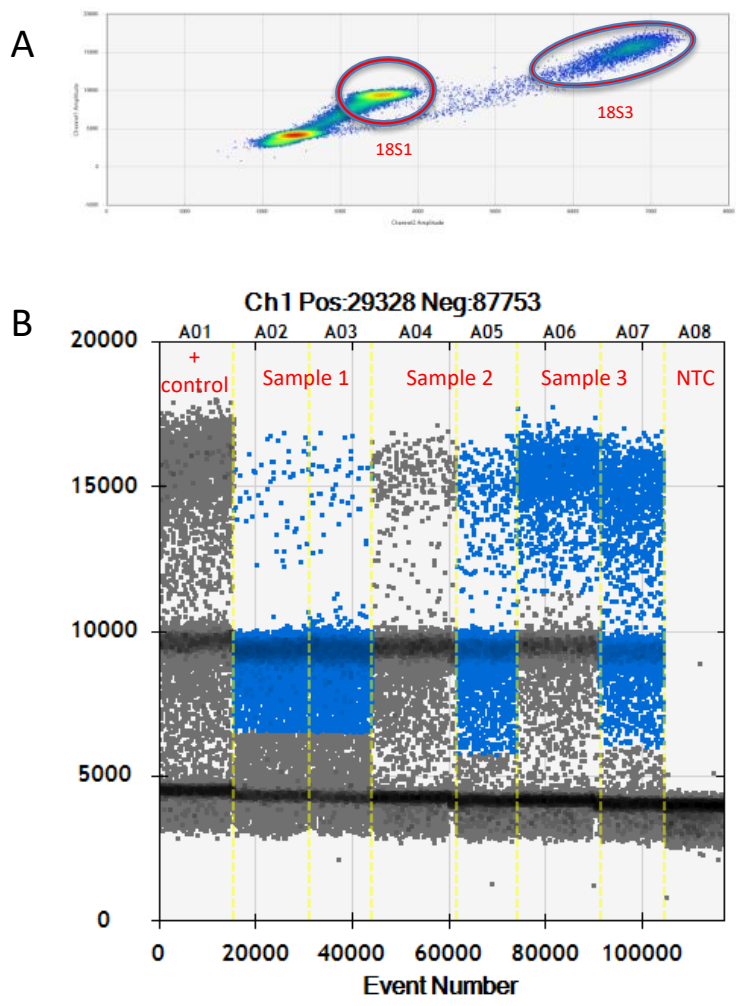

Figure 4. Comparison of $18 \mathrm{~S} 3$ to $18 \mathrm{~S} 1$. (A) Sufficient droplet separation was achieved, and distinct populations could be selected for quantification. (B) However, a large amount of variability in the mean ratio, .153 ( $\mathrm{s}=.222$ ), of $18 \mathrm{~S} 3$ to $18 \mathrm{~S} 1$ was observed. 


\section{Discussion}

The aim of this set of experiments was to determine if ddPCR had the potential to improve the ability to estimate the age of a bloodstain. Droplet digital PCR was expected to improve upon the previously established qPCR assay due to its increased sensitivity, robustness to inhibitors, droplet partitioning, and decreased reliance on reaction efficiency for accurate quantification ${ }^{10,13}$. These claims were unable to be supported by the results of this study.

Despite designing a positive control that should produce a 1:1 ratio of amplicons in copy number per microliter, we consistently observed a much lower ratio of .288 copies of large to small amplicon. This suggests that reaction efficiency is still an important consideration in ddPCR assays, even if it is not as much of a concern as in qPCR assays. Despite this setback, we were able to use the experimentally determined ratio as a baseline and continue on with experimental samples due to its reproducibility.

When studying the ratio of large to small fragments of Beta-actin, it was determined that there was no difference in the ratio of large to small fragments over time. Furthermore, an aged blood study was not conducted using the $18 \mathrm{~S}$ primer sets due to the high variability in the ratios observed when the primer sets were tested in fresh blood. This data would suggest that ddPCR is not suitable for use in determining the age of a bloodstain.

However, the variability in these measurements could be attributed to the multistep process required to prepare these samples for PCR rather than the ddPCR itself. In order to examine two amplicons on the same RNA molecule, a second strand synthesis, purification, and restriction digestion step had to be added to the experimental workflow. Each step in this process is another possible place for variability and error to be introduced into the assay. Although ddPCR has the ability to be multiplexed with evagreen dye and provide results 
comparable to TaqMan assays ${ }^{14}$, it is clearly not the ideal option for this particular experimental design.

This assay could be improved by switching to a TaqMan reaction chemistry where fluorescently labeled probes could bind to the different amplicons and they would be identified by the probe rather than the fluorescence amplitude of the droplets. This would allow for ddPCR to occur directly following cDNA synthesis and would likely decrease some of the variability observed in the measurements. However, it is possible that this design would lead to less accurate quantification because the targets will still be linked. When the two targets in ddPCR are linked in cis, inaccurate quantification can occur because the equations used rely on the assumption of independent assortment of the targets into different droplets ${ }^{15}$. However, it may be possible to perform multiple singleplex reactions and calculate ratios of different targets to each other. While it was not extensively tested in this study, it was observed that the copies/microliter of BA89 and BA301 present in the positive control sample were approximately the same when measured in singleplex and multiplex reactions. Another group has also shown this to be true ${ }^{16}$, so it may be an option for future assay design with more extensive testing.

Alternatively, a comparison between targets on different mRNA molecules could be used to estimate the age of a bloodstain. Anderson et al. (2005) had success comparing Beta-actin mRNA to $18 \mathrm{~S}$ rRNA as a way to estimate the age of a bloodstain. In this scenario, mRNA was found to degrade more rapidly than $18 \mathrm{~S}$ rRNA and the decrease in ratio of Beta-actin to $18 \mathrm{~S}$ was able to be linked to the age of a bloodstain ${ }^{4}$.

In the context of this study, it is more logical to attempt to compare amplicons on different RNA molecules due to the increased cost that using fluorescent probes, or multiple singleplex reactions would present. It is important to continue research that may lead to a high 
quality assay that can be implemented in crime laboratories in order to estimate the age of biological fluids. 


\section{Comparison of different RNA molecules to estimate the age of a bloodstain. Introduction}

Estimating the age of biological evidence left at crime scenes, specifically the age of bloodstains, has confounded the forensic research community for many years. One method that has been of particular interest is the study of RNA degradation. This method involves measuring relative quantities of RNA present in dried stains in order to estimate how long the biological fluid has been present ex vivo ${ }^{2,4,5}$. While this method has previously been attempted using quantitative PCR, we have attempted to improve upon the assay by using the more sensitive droplet digital PCR technology.

The first chapter of this thesis attempted to use ddPCR to estimate the age of bloodstains using relative ratios of large to small fragments of the same RNA species (either Beta-actin or 18S). While we found that ddPCR was not superior to qPCR in this case, it remains unclear if ddPCR could provide an advantage when multiplexing targets on different RNA molecules. It has previously been shown that the relative ratio of Beta-actin mRNA to 18S rRNA decreases over time as they randomly decay at different rates in dried stains ${ }^{4}$. This is thought to be because of the fact that mRNA is more exposed whereas rRNA is more protected from degradation by the proteins it is complexed with.

Here, we aim to make the comparison between Beta-actin mRNA and 18S rRNA to determine if this type of assay can be adapted to ddPCR. We will also expand upon what was previously done by comparing a small fragment of Beta-actin to a large fragment of Beta-2microglobulin. This is of particular interest because using two different genes will allow for a simplified multiplexed ddPCR reaction in comparison to the multiplex reaction where both amplicons are on the same RNA transcript. There is no evidence to suggest that one species of 
mRNA will decay faster than the other in ex vivo samples and both Beta-actin and Beta-2microglobulin are housekeeping genes that have been shown to be stably expressed in forensic

samples ${ }^{17,18}$. If we can demonstrate that this type of assay is effective in estimating the age of a bloodstain, it could easily be applied to other biological fluids. Furthermore, additional multiplex reactions could be developed using other pairs of housekeeping genes in order to strengthen the statistical power of the assay.

\section{Methods}

\section{Gene Selection and Primer Design}

A literature search was performed to identify candidate housekeeping genes. We were particularly interested in those that would be present in high abundance in forensic samples so that the assay would have a longer timeframe in which it would be applicable. Once genes were selected, primers were designed using primer 3 express software. We were unable to design primers that spanned an exon-exon junction to prevent binding to genomic DNA. However, where possible, primer pairs were chosen so that the amplicon would span an exon-exon junction. This would allow for easy identification of DNA contamination because products of DNA amplification would be significantly large than those from amplification of the intended cDNA. Primer sequences used in this chapter can be found in Table 2. Primers were tested in multiplex reactions using temperature gradients to identify the optimal annealing temperature for droplet separation. BA89 and 18S1 were compared in singleplex reactions to determine if there would be enough separation in their droplet populations due to their relatively smaller size difference. Dilution series were performed to identify the optimal dilution range for input cDNA samples. 
Table 2. Primer sequences for comparisons between different RNA species. *Indicates previously published primers $^{5}$.

\begin{tabular}{|l|l|l|l|}
\hline Name & Gene & $\begin{array}{l}\text { Amplicon } \\
\text { Size }\end{array}$ & \begin{tabular}{l} 
Primer Sequences \\
\hline BA89*
\end{tabular} \\
\hline Beta-actin mRNA & 89 bp & $\begin{array}{l}\text { FP: 5' TCA TTC CAA ATA TGA GAT GCA TTG T 3' } \\
\text { RP: 5' GGA CTG GGC CAT TCT CCT TAG 3' }\end{array}$ \\
\hline $18 S 1$ & 18S rRNA & 63 bp & $\begin{array}{l}\text { FP: 5' GGG ATC GGG GAT TGC AAT TA 3' } \\
\text { RP: 5' GCT TAT GAC CCG CAC TTA CT 3' }\end{array}$ \\
\hline B2Ma & $\begin{array}{l}\text { Beta-2-microglobulin } \\
\text { mRNA }\end{array}$ & 293 bp & $\begin{array}{l}\text { FP: 5' TAG CTG TGC TCG CGC TAC TC 3' } \\
\text { RP: 5' ATG GTT CAC ACG GCA GGC AT 3' }\end{array}$ \\
\hline
\end{tabular}

\section{Sample Collection}

Blood was spotted on cotton cloth from a single female donor. Three, $10 \mu \mathrm{L}$ aliquots of blood were used for each time point. The bloodstains were allowed to age at ambient conditions in a designated section of the lab. RNA was isolated from fresh, 1, 2, 3, 4, 6, 8, 10, and 12-weekold bloodstains.

\section{RNA Isolation and cDNA Synthesis}

Bloodstains were cut from the cotton cloth and added to $200 \mu \mathrm{L}$ of nuclease free water, 3 $\mu \mathrm{L}$ of cold $\left(4^{\circ} \mathrm{C}\right)$ polyacryl carrier, and $750 \mu \mathrm{L}$ of RNAzol BD (Molecular Research Center). The samples were vortexed then incubated in a $50^{\circ} \mathrm{C}$ water bath for 10 minutes. One hundred microliters of 1-bromo-3-chloropropane (BCP) was added to the samples to assist in phase separation. The tubes were vortexed for 15 seconds and allowed to incubate at room temperature for 3 minutes. Following incubation, the samples were centrifuged at 12,000xg for 15 minutes. The aqueous layer was transferred to a new RNase free tube and $500 \mu \mathrm{L}$ of cold $\left(4^{\circ} \mathrm{C}\right)$ isopropanol was added; tubes were inverted to mix the aqueous layer and isopropanol and allowed to incubate at room temperature for 7 minutes. Samples were then centrifuged at 12,000xg for 8 minutes. After centrifugation, the supernatant was discarded, and $1 \mathrm{~mL}$ of $75 \%$ 
ethanol was added to wash the RNA pellet. The pellet and ethanol were briefly vortexed and then centrifuged for 5 minutes at $12,000 \mathrm{xg}$. The ethanol wash step was repeated, then the supernatant was removed, and the pellets were allowed to air dry for approximately 5 minutes. Twenty microliters of RNase free water was added to the pellet and then incubated at $55^{\circ} \mathrm{C}$ for 10 minutes. Immediately following RNA isolation, cDNA synthesis was performed. The iScript cDNA Synthesis Kit RT-qPCR (Bio-Rad) was used according to manufacturer's instructions. Five microliters of input RNA was added.

\section{Droplet Digital PCR}

Samples were prepped at a volume of $22 \mu \mathrm{L}$ using the QX200 ddPCR EvaGreen Supermix. All primers were added at a final concentration of $100 \mathrm{~nm}$ and $2 \mu \mathrm{L}$ of template was added to each reaction. Before completing aged studies, temperature gradients and dilution series were used to determine the optimal annealing temperature and dilution of template to be used in the assay. Two technical replicates were prepared for each biological replicate in the analysis of aged bloodstains. Following preparation of the $22 \mu \mathrm{L}$ PCR reactions, $20 \mu \mathrm{L}$ of each was added to a droplet generation cartridge along with $70 \mu \mathrm{L}$ of droplet generation oil. After droplet partitioning by the QX 200 Droplet Generator (Bio-Rad), the samples were transferred to a 96 well plate using a multichannel pipet. The plate was heat-sealed and PCR was performed using the $\mathrm{C} 1000$ Touch Thermal Cycler (Bio-Rad) under the following cycling conditions: $95^{\circ} \mathrm{C}$ for 5 minutes, 40 cycles of $95^{\circ} \mathrm{C}$ for 30 seconds then $58^{\circ} \mathrm{C}$ for 1 minute, $4^{\circ} \mathrm{C}$ for 5 minutes, $90^{\circ} \mathrm{C}$ for 5 minutes, and then an infinite hold at $4^{\circ} \mathrm{C}$. The lid temperature was set to $105^{\circ} \mathrm{C}$ and the reaction volume was set at $40 \mu \mathrm{L}$. 


\section{Data Analysis}

Droplet digital PCR data was analyzed using the QuantaSoft Analysis Pro software. Thresholds were drawn between droplet populations and the software

used Poisson statistics to identify the quantity of starting material present for each amplicon in copies per microliter ${ }^{9}$. The ratio of large to small fragment was calculated for each sample and these ratios were used for downstream statistical analyses. An ANOVA was performed using ratios of aged blood samples in order to determine if the ratio of large to small fragment was significantly different for different ages of bloodstains.

\section{Results}

Comparison of $m R N A$ to $r R N A$

We first attempted to determine if it was possible to compare Beta-actin mRNA (BA89) to $18 \mathrm{~S}$ rRNA (18S1) using ddPCR. Singleplex reactions of each were compared to determine if there would be enough separation in the fluorescent amplitude of the droplet populations to allow for a multiplex between these two primer sets. We found that in order to achieve quantification of the $18 \mathrm{~S}$ rRNA transcript, it was necessary to dilute the sample to the point where the Betaactin mRNA was no longer detected (Fig. 5). Therefore, multiplexing a Beta-actin amplicon with an $18 \mathrm{~S}$ amplicon is not an option using ddPCR. 


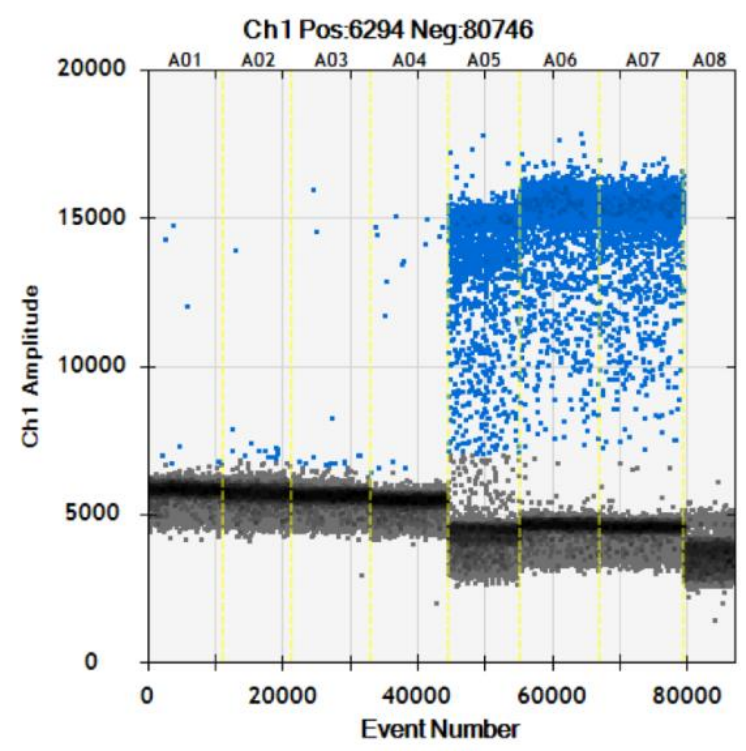

Figure 5. Comparison of Beta-actin to 18S transcripts. 18S rRNA (A05-A07) is much more concentrated and requires dilution of the input cDNA to the point where Beta-actin (A02-A04) is no longer detectable.

\section{Comparison of Beta-actin to Beta-2-microglobulin}

Beta-actin and Beta-2-microglobulin were able to be successfully multiplexed, and the ratio of B2Ma to BA89 was measured at multiple timepoints. There was no significant difference in the ratio of B2Ma to BA89 between any of the timepoints measured $[\mathrm{F}=2.5883$, $\mathrm{p}=.0502]$. In addition to there being no significant difference in any of the time points, there does not appear to be any pattern emerging regarding the change in ratio over time (Fig 6.). 


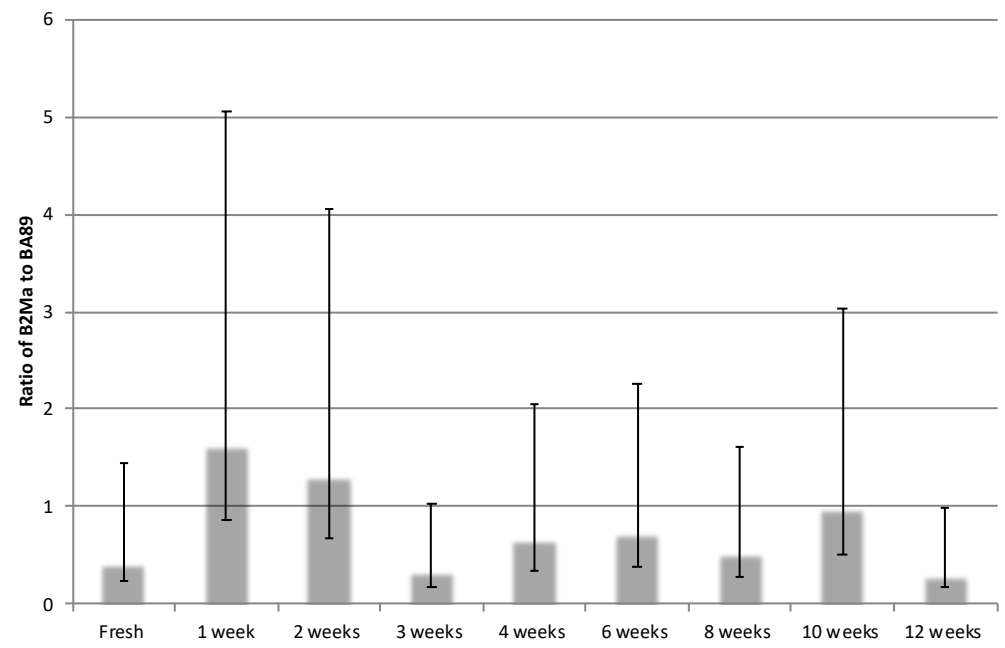

Figure 6. Average ratio of B2Ma to BA89 in aged bloodstains. There was no significant difference in the ratio between timepoints $[\mathrm{F}=2.5883, \mathrm{p}=.0502]$. Bars represent the $95 \%$ confidence interval.

\section{Discussion}

The main objective of this study was to determine if rates of degradation between different RNA molecules could be used to estimate the age of a bloodstain using ddPCR. Based on the results above, this does not appear to be possible. Comparing mRNA to rRNA (Fig. 4), was unsuccessful largely due to the dynamic range of the ddPCR machine. Because the Quantasoft software uses a Poisson distribution to provide an absolute quantification of the target, it is imperative that there are both positive (contains target) and negative (does not contain target) droplets in the reaction. Therefore, if too many copies of target cDNA are present quantification is not possible and the input sample must be diluted ${ }^{19-21}$. Ribosomal RNA accounts for the majority of RNA in a cell and is far more abundant than mRNA, so it is unlikely that any comparison of mRNA to rRNA would be possible using ddPCR ${ }^{22}$.

Our attempts to use a large fragment of beta-2-microglobulin compared to a small fragment of Beta-actin were also unsuccessful (Fig. 6). This could be due to variability in the amount of starting mRNA in the sample. It is also possible that the fact that there is more Beta2-microglobulin present in blood samples than Beta-actin could affect the change in the ratio 
over time ${ }^{18}$. The comparison between a small and large fragment is based on the idea that a random degradation event is more likely to occur within a large area more often than within a small area. While this has been shown to work well where both segments are part of the same RNA transcript ${ }^{5}$, using two different RNA transcripts complicates this design by adding extra variables. These include the amount of starting material and the possibility that the more abundant RNA species will incur more degradation events.

Although our attempts to estimate the age of a bloodstain using ddPCR were unsuccessful, measuring relative rates of RNA degradation using qPCR is still a viable option. It has been previously shown that estimating the age of bloodstains using qPCR is possible using both comparison of mRNA and rRNA, and small and large fragments on the same RNA transcript ${ }^{4,5}$. Quantitative PCR is also cheaper than digital PCR ${ }^{23}$, and less time consuming. Furthermore, forensic laboratories that perform STR analysis will already have a qPCR machine that they use for quantifying DNA samples and would not have to invest in the costly droplet digital PCR equipment in order to implement those assays.

Future research should focus on expanding the usefulness of the previously published assays for estimating the age of a bloodstain. Droplet digital PCR was originally attempted to help alleviate preferential amplification of the smaller fragment in the qPCR assays ${ }^{5}$. An alternative approach may be to use similarly sized amplicons and make several comparisons between different mRNA and rRNA transcripts. This would allow for a multivariate approach that can strengthen the statistical power of the assay.

In conclusion, digital PCR does not provide significant advantages over quantitative PCR in terms of estimating the age of a bloodstain. However, examining relative rates of RNA 
degradation remains the most promising method for estimating the age of all biological fluids over a large time period, and attempts to improve these assays should continue. 


\section{Bibliography}

1. Gehrig C, Teyssier A. Forensic DNA Analysis. CHIMIA International Journal for Chemistry [Internet] 2002 [cited 2017 Mar 5];56(3):71-3. Available from:

http://www.ingentaselect.com/rpsv/cgi-

bin/cgi?ini=xref\&body=linker\&reqdoi $=10.2533 / 000942902777680784$

2. Bremmer RH, de Bruin KG, van Gemert MJC, van Leeuwen TG, Aalders MCG. Forensic quest for age determination of bloodstains. Forensic Science International [Internet] 2012 [cited 2017 Aug 13];216(1-3):1-11. Available from:

http://linkinghub.elsevier.com/retrieve/pii/S0379073811003598

3. Shin J, Choi S, Yang J-S, Song J, Choi J-S, Jung H-I. Smart Forensic Phone: Colorimetric analysis of a bloodstain for age estimation using a smartphone. Sensors and Actuators B: Chemical [Internet] 2017 [cited 2019 Jan 10];243:221-5. Available from: http://www.sciencedirect.com/science/article/pii/S0925400516319402

4. Anderson S, Howard B, Hobbs GR, Bishop CP. A method for determining the age of a bloodstain. Forensic Science International 2005;148(1):37-45.

5. Anderson SE, Hobbs GR, Bishop CP. Multivariate Analysis for Estimating the Age of a Bloodstain*. Journal of Forensic Sciences [Internet] 2011 [cited 2019 Feb 25];56(1):18693. Available from: https://onlinelibrary.wiley.com/doi/abs/10.1111/j.15564029.2010.01551.x

6. Bauer M, Polzin S, Patzelt D. Quantification of RNA degradation by semi-quantitative duplex and competitive RT-PCR: a possible indicator of the age of bloodstains? Forensic Science International [Internet] 2003 [cited 2018 Nov 29];138(1):94-103. Available from: http://www.sciencedirect.com/science/article/pii/S037907380300392X

7. Bustin SA, Nolan T. Pitfalls of quantitative real-time reverse-transcription polymerase chain reaction. Journal of biomolecular techniques : JBT [Internet] 2004 [cited 2017 Aug 10];15(3):155-66. Available from: http://www.ncbi.nlm.nih.gov/pubmed/15331581

8. Geng T, Mathies RA. Minimizing inhibition of PCR-STR typing using digital agarose droplet microfluidics. 2015;

9. Bio-Rad Laboratories Inc. Droplet Digital PCR (ddPCR) Technology. 2016;

10. Hindson CM, Chevillet JR, Briggs HA, Gallichotte EN, Ruf IK, Hindson BJ, et al. Absolute quantification by droplet digital PCR versus analog real-time PCR. Nature methods [Internet] 2013 [cited 2016 Sep 11];10(10):1003-5. Available from: http://www.ncbi.nlm.nih.gov/pubmed/23995387

11. Campomenosi P, Gini E, Noonan DM, Poli A, D’Antona P, Rotolo N, et al. A comparison between quantitative PCR and droplet digital PCR technologies for circulating microRNA quantification in human lung cancer. BMC Biotechnology [Internet] 2016 [cited 2016 Sep 
26];16(1):60. Available from:

http://bmcbiotechnol.biomedcentral.com/articles/10.1186/s12896-016-0292-7

12. Patrick Kolar W. The Effects of Known PCR Inhibitors on Droplet Digital PCR Performance. 2015 [cited 2016 Oct 24];A vailable from:

http://digitalcommons.hsc.unt.edu/theses

13. Young ST, Wells JD, Hobbs GR, Bishop CP. Estimating postmortem interval using RNA degradation and morphological changes in tooth pulp. Forensic Science International [Internet] 2013 [cited 2019 Feb 15];229(1-3):163.e1-163.e6. Available from: https://linkinghub.elsevier.com/retrieve/pii/S0379073813001916

14. McDermott GP, Do D, Litterst CM, Maar D, Hindson CM, Steenblock ER, et al. Multiplexed Target Detection Using DNA-Binding Dye Chemistry in Droplet Digital PCR. Anal Chem [Internet] 2013 [cited 2019 Jan 17];85(23):11619-27. Available from: https://doi.org/10.1021/ac403061n

15. Whale AS, Huggett JF, Tzonev S. Fundamentals of multiplexing with digital PCR. Biomolecular Detection and Quantification [Internet] 2016 [cited 2019 Mar 21];10:15-23. Available from: http://www.sciencedirect.com/science/article/pii/S2214753516300092

16. McDermott GP, Do D, Litterst CM, Maar D, Hindson CM, Steenblock ER, et al. Multiplexed Target Detection Using DNA-Binding Dye Chemistry in Droplet Digital PCR. Analytical Chemistry [Internet] 2013 [cited 2016 Sep 26];85(23):11619-27. Available from: http://pubs.acs.org/doi/abs/10.1021/ac403061n

17. Dheda K, Huggett JF, Bustin SA, Johnson MA, Rook G, Zumla A. Validation of housekeeping genes for normalizing RNA expression in real-time PCR. BioTechniques 2004;37(1).

18. Moreno LI, Tate CM, Knott EL, McDaniel JE, Rogers SS, Koons BW, et al. Determination of an Effective Housekeeping Gene for the Quantification of mRNA for Forensic Applications*. Journal of Forensic Sciences [Internet] 2012 [cited 2017 Feb 21];57(4):1051-8. Available from: http://doi.wiley.com/10.1111/j.1556-4029.2012.02086.x

19. Vogelstein B, Kinzler KW. Digital PCR. Proceedings of the National Academy of Sciences of the United States of America [Internet] 1999 [cited 2016 Nov 14];96(16):923641. Available from: http://www.ncbi.nlm.nih.gov/pubmed/10430926

20. Baker M. Digital PCR hits its stride. Nature Methods [Internet] 2012 [cited 2016 Sep 8];9(6):541-4. Available from: http://www.nature.com/doifinder/10.1038/nmeth.2027

21. Doi H, Takahara T, Minamoto T, Matsuhashi S, Uchii K, Yamanaka H. Droplet Digital Polymerase Chain Reaction (PCR) Outperforms Real-Time PCR in the Detection of Environmental DNA from an Invasive Fish Species. Environmental Science \& Technology [Internet] 2015 [cited 2016 Nov 20];49(9):5601-8. Available from: http://pubs.acs.org/doi/abs/10.1021/acs.est.5b00253 
22. Olsvik PA, Lie KK, Jordal A-EO, Nilsen TO, Hordvik I. Evaluation of potential reference genes in real-time RT-PCR studies of Atlantic salmon. BMC Molecular Biology [Internet] 2005 [cited 2019 Mar 20];6(1):21. Available from: https://doi.org/10.1186/1471-2199-6-21

23. Verhaegen B, De Reu K, De Zutter L, Verstraete K, Heyndrickx M, Van Coillie E. Comparison of Droplet Digital PCR and qPCR for the Quantification of Shiga ToxinProducing Escherichia coli in Bovine Feces. Toxins (Basel) [Internet] 2016 [cited 2019 Mar 20];8(5). Available from: https://www.ncbi.nlm.nih.gov/pmc/articles/PMC4885071/ 